\title{
Two Decades of Research and Development in Transformational Leadership
}

\author{
Bernard M. Bass \\ Center for Leadership Studies, State University of New York, \\ Binghamton, USA
}

\begin{abstract}
The interests of the organization and its members need to be aligned. Such is a task for the transformational leader. In contrast to the transactional leader who practises contingent reinforcement of followers, the transformational leader inspires, intellectually stimulates, and is individually considerate of them. Transformational leadership may be directive or participative. Requiring higher moral development, transformational leadership is recognized universally as a concept. Furthermore, contrary to earlier expectations, women leaders tend to be more transformational than their male counterparts. Although a six-factor model of transformational/ transactional leadership best fits a diversity of samples according to confirmatory factor analyses, whether fewer factors are necessary remains an open question. Another important research question that has only been partially answered is why transformational leadership is more effective than transactional leadership in a wide variety of business, military, industrial, hospital, and educational circumstances.
\end{abstract}

\section{INTRODUCTION}

It has been 20 years since Burns (1978) published his seminal work introducing the concepts of transformational and transactional leadership. Whereas transformational leaders uplift the morale, motivation, and morals of their followers, transactional leaders cater to their followers' immediate self-interests. The transformational leader emphasizes what you can do for your country; the transactional leader, on what your country can do for you. A considerable amount of empirical research has been completed since then, supporting the utility of the distinction. Changes in the marketplace and workforce over the two decades have resulted in the need for leaders to become more transformational and less transactional if they were to remain effective. Leaders were encouraged to empower their followers by developing them into high involvement individuals and teams focused on quality, service, cost-effectiveness, and quantity of output

Requests for reprints should be addressed to B.M. Bass, Center for Leadership Studies, State University of New York, Binghamton, New York, 13902-6015, USA: email: bbass@binghamton.edu 
of production. The end of the Cold War placed a premium on the flexibility of employees, teams, and organizations. Jobs for the less skilled were automated out of existence or exported to the Third World. Those jobs that remained required better education and training.

Responsibility shifted downward in the flattening organizational hierarchy. Teams of educated professionals became commonplace. Increasingly, professionals saw themselves as colleagues rather than in superior-subordinate relationships. Transformational leadership, which fosters autonomy and challenging work, became increasingly important to followers' job satisfaction. The concept of job security and loyalty to the firm for one's entire career was disappearing. Steady pay, secure benefits, and lifetime employment were no longer guaranteed for meritorious performance. At the same time, transactional leadership alone could not provide job satisfaction.

Forty years ago in the United States, parents believed that it was most important to teach their children to respect authority, to respect the church, to respect one's government, and to avoid questioning authority. Today parents believe it is most important to teach their children to accept responsibility for their own actions, to be willing and confident in accepting challenges, and to question authority when necessary. The conforming organizational worker of the 1950 s, totally dedicated to the firm, did not question authority. In the 1990s, much scepticism and cynicism has replaced the norms of unquestioning conformity of the 1950s.

In the 1950s, going beyond one's self-interests for the good of the organization was a norm of the organizational worker. That is, there was public and expressed acceptance of organizational goals, possibly filled with private reservations. There may have been a lot of expressed identification with the organization's goals and even internalization of the organization's beliefs. In today's more cynical world, such going beyond one's self-interests for the good of the organization requires aligning the individual members' interests and values with those of the organization. Trust in the leadership is required for willingness to identify with the organization and to internalize its values and the emergence in the workforce of transcendental organizational citizenship behaviour (altruism, conscientiousness, sportsmanship, courtesy, and civic virtues) (Podsakoff, MacKenzie, Moorman, \& Fetter, 1990). For this, transformational leadership is needed along with corresponding changes in selection, training, development, and organizational policies.

\section{The Full Range of Transactional and Transformational Leadership}

Much has been done but more still needs to be done before we can fully understand and confidently make use of the full range of transactional and transformational leadership. Transactional leadership refers to the exchange relationship between leader and follower to meet their own self-interests. It may 
take the form of contingent reward in which the leader clarifies for the follower through direction or participation what the follower needs to do to be rewarded for the effort. It may take the form of active management-by-exception, in which the leader monitors the follower's performance and takes corrective action if the follower fails to meet standards. Or it may take the form of passive leadership, in which the leader practises passive managing-by-exception by waiting for problems to arise before taking corrective action or is laissez-faire and avoids taking any action.

Transformational leadership refers to the leader moving the follower beyond immediate self-interests through idealized influence (charisma), inspiration, intellectual stimulation, or individualized consideration. It elevates the follower's level of maturity and ideals as well as concerns for achievement, selfactualization, and the well-being of others, the organization, and society. Idealized influence and inspirational leadership are displayed when the leader envisions a desirable future, articulates how it can be reached, sets an example to be followed, sets high standards of performance, and shows determination and confidence. Followers want to identify with such leadership. Intellectual stimulation is displayed when the leader helps followers to become more innovative and creative. Individualized consideration is displayed when leaders pay attention to the developmental needs of followers and support and coach the development of their followers. The leaders delegate assignments as opportunities for growth.

The full range of leadership, as measured by the Multifactor Leadership Questionnaire (MLQ), implies that every leader displays a frequency of both the transactional and transformational factors, but each leader's profile involves more of one and less of the other. Those leaders who are more satisfying to their followers and who are more effective as leaders are more transformational and less transactional (Avolio \& Bass, 1991).

The transactional and transformational rubric can be applied to teams as a whole and to organizations as a whole. Members of transformational teams care about each other, intellectually stimulate each other, inspire each other, and identify with the team's goals. Transformational teams are high-performing. Organizational policies and practices can promote employee empowerment, creative flexibility and esprit de corps.

In the same way, the paradigm can be extended to international relations, which can be conceived in terms of the extent emphasis is laid on principles (transformational) or power politics (transactional). When Pius XII talks about principles of morality, Joseph Stalin asks how many army divisions the Pope commands. When the United States sends American troops into harm's way in Bosnia, is it because US economic and political interests are threatened or is it to uphold principles of morality, humanitarianism, and world peace?

Recently, (Bass, 1998) I have reviewed what we know from research about how transformational leadership enhances commitment, involvement, loyalty, and performance of followers; how transactional leadership may induce more 
stress; how transformational leadership helps deal with stress among followers; and how contingencies in the environment, organization, task, goals, and relationships affect the utility of transactional and transformational leadership. Transactional leadership can be reasonably satisfying and effective but transformational leadership adds substantially to the impact of transactional leadership.

We have also learned about the effects of organizational culture and policies, and the effects of sex differences on transformational leadership. We have learned somewhat about how and what could be taught about the subject and how to predict which leaders are more likely to become more transactional or transformational. Research has been completed on whether rank and status are of consequence to exhibiting transformational leadership, or are as present among first-line supervisors and squad leaders as among CEOs and brigade commanders.

\section{Going Beyond Self-actualization}

The importance of transcending self-interests is something lost sight of by those who see that the ultimate in maturity of development is self-actualization. Consistent with Burns (1978), Handy (1994, p. 275) pointed out that Maslow's (1954) hierarchy of needs must be further elevated to go beyond one's selforiented concerns:

there [should] be a stage beyond self-realization, a stage [of] ... idealization, the pursuit of an ideal or a cause that is more than oneself. It is this extra stage that would redeem the self-centered tone of Maslow's thesis, which for all that it rings true of much of our experience, has a rather bitter aftertaste.

In 1978, Burns had handled this possible bitter aftertaste by describing the transforming leader as one who not only moved followers up on Maslow's hierarchy, but also moved them to transcend their own self-interests, presumably including their own self-realization. Williams (1994) showed that transformational leaders display more citizenship behaviours such as altruism, conscientiousness, sportsmanship, courtesy, and civic virtue, as well as imbue their subordinates with these same values.

Avolio and Bass (1991) chose to substitute for the term "charisma", in training and elsewhere, the term idealized influence, that is, being influential about ideals. At the highest level of morality are selfless ideal causes to which leaders and followers may dedicate themselves. Serving one's country to the best of one's abilities can be a powerful motivator.

We need to investigate the potential conflict of the would-be transformational leaders' motivation to achieve and self-actualize while focusing their efforts for the greater good for group, organization, or society. The resolution may lie in the 
alignment of personal principles with those of the group, organization, and society. One paradox for us may be that as we push the transformational process, particularly focusing on development of followers, we may shortchange the transcending of followers' self-interests. The transformational leader needs to do both by aligning the followers' self-interests in their own development with the interests of the group, organization, or society.

A related example concerns military officers who are faced with threats to their careers if, as they obey their code of honour, they notify authorities of unethical behaviour they observe in fellow officers. For in doing so they violate the quality of relationships they are expected to maintain with fellow officers in order to conform to a principle enunciated in the honour code. Whistle blowers in any organization often must choose as a matter of conscience between revealing unethical or illegal behaviour in others and avoiding risks to their achieving their career goals.

\section{RELATED CONCEPTS AND MEASURES}

The transactional/transformational paradigm is independent conceptually from the concepts of directive versus participative leadership, leader-member exchange (LMX), and the factor of consideration as measured by the Leader Behaviour Description Questionnaire, although empirical correlations with them may be found to some extent.

\section{Directive and Participative Leadership}

Transformational leaders can be directive or participative, authoritarian or democratic. Nelson Mandela is directive and transformational when he declares "Forget the past". He can be participative and transformational when he actively supports and involves himself in open, multiracial consultations. He can be directive and transactional when he promises blacks better housing in exchange for their votes and is participative and transactional when he reaches mutual agreements about sharing power with the white minority. The same leaders display both transformational and transactional behaviour as well as mix direction and participation.

\section{Leader-member Exchange}

Leader-member exchange (LMX) concentrates on the perceived quality of the dyadic relationship between a subordinate and his or her immediate supervisor (Graen \& Scandura, 1986). Tejeda and Scandura (1994) examined the relationship among supervisors and subordinates in a health-care organization in terms of both transformational leadership and leader-member exchange. This had been preceded by attempts by Yukl (1989) to deal with LMX as transactional leadership because of LMX's reliance on exchange of rewards. However, subsequent 
examination of the development process in LMX by Graen and Uhl-Bien (1991) led to their reframing LMX as a transactional and a transformational leadership process. LMX unfolds in several stages in which trust, loyalty, and respect develop. In the first stage, LMX is transactional. If the last stage is reached, it is transformational.

\section{LBDQ Consideration}

Individualized consideration, as measured by the Multifactor Leadership Questionnaire (MLQ), is conceptually distinct from the Leader Behaviour Description Questionnaire (LBDQ) scale of consideration, although they are empirically correlated. Seltzer and Bass (1990) reported a correlation of 0.69. LBDQ consideration focuses on friendliness, approachability, and participative decision making; individualized consideration deals with concern for each follower as an individual and with the follower's development. It includes (Bass \& Avolio, 1993a, p. 64): “knowing your followers' needs and raising them to more mature levels ... [and using] delegation to provide opportunities for each follower to self-actualize and to attain higher standards of moral development. Some leaders can be quite directive rather than participative in such actions."

According to data collected by Seltzer and Bass (1990), LBDQ initiation and consideration may substitute for transactional leadership, but not for transformational leadership. Much additional variance in effectiveness was accounted for by adding the MLQ transformational leadership scores to the LBDQ initiation and consideration scores in multiple regression equations. Furthermore, there are "highly reliable differences among the conceptions of managers, project supervisors, CEOs, military officers, principals, and other administrators in the distinctions between transactional leadership, transformational leadership, and LBDQ consideration and initiation of structure" (Bass \& Avolio, 1993a, p. 65).

\section{TRAINING, EDUCATION, AND DEVELOPMENT}

Transformational and transactional leadership are affected by moral and personal development, and training and education.

\section{Moral and Personal Development}

Mature moral development is required of the transformational leader (Kuhnert \& Lewis, 1987). One's parents' moral standards, and one's leadership experiences in school and extracurricular activities, forecast subsequent tendencies to be more transformational as adult leaders (Avolio, 1994). Avolio and Gibbons (1988) reported that industrial executives who were rated by their immediate subordinates as highly transformational, reported in retrospective interviews that their parents provided them with difficult challenges but also supported the 
nascent leaders' efforts whether or not they resulted in success (Gibbons, 1986). Similarly, transformational community leaders described childhood and adolescent experiences with caring but challenging parents who held high standards. Schools also made a difference, as did work experiences as a young adult (Avolio \& Bass, 1994). The immature, self-aggrandizing charismatic is pseudotransformational. He or she may seem uplifting and responsible but on closer examination is found to be a false Messiah. Much more needs to be learned about the ethical and moral factors that distinguish the truly transformational leader from the pseudotransformational leader.

\section{Training and Education}

Intuitively, teaching and learning about how to be more or less constructive and corrective as a transactional leader should not be too difficult. More difficult is developing both the willingness and ability to be more transformational. Nevertheless, it is doable. Self-reports, incidents, and collegial ratings from the workplace have been collected from 200 executives and 500 community leaders which have validated the impact of the "Full Range of Leadership Development", a comprehensive training programme. Generally, positive results have been obtained. Follow-ups six months to two years later suggest modest improvements in transformational leadership, particularly in those transformational factors on which participants made plans to improve. These improvements tend to be accompanied by a reduction in the use of managing-by-exception (Bass \& Avolio, 1990b, 1998).

Training to increase transformational leader behaviours begins with an examination of the implicit theories of ideal leadership that trainees carry around in their heads. The leadership is transformational and contingent rewarding. But why don't trainees practise more of it? Cases are reviewed to clarify the distinctions among the transformational and transactional leadership behaviours. A 360-degree assessment of these behaviours of all the trainees is provided from those back in the organization to which the trainees belong.

The trainees are helped to make plans on how to improve their profiles of behaviours and to deal with perceived obstacles to change. Assistance is provided by facilitators and fellow trainees. The trainees returns to their respective workplaces for three months to pursue their individual plans. Then, in a followup programme, the trainees review the success of their plans, revise them, and learn more about what they can do to be more transformational as a force for change in their organizational culture. Finally, they videotape their vision of their organization in two to five years to align the interests of their followers, themselves, and other stakeholders.

It will be possible to individualize the assessment and training programme through an available website in which the individual trainee receives follow-up suggestions over a 30-day period (http://leadership.mindgarden.com). 


\section{CONTINGENCIES}

A case can be made for the universality of the concepts of transformational and transactional leadership (Bass, 1997). Although the original theory, model, and measurements emerged in the individualistic United States, it appears equally or even more applicable in the collectivist societies of Asia. Collectivist cultures provide the leaders with ready-made opportunities to become transformational leaders. Most subordinates in collectivist cultures already have respect for their leaders. Transformational leadership is more likely to be enhanced further by centrality of work in life and the high level of group orientation among followers.

The mutual obligation between the leaders and the followers facilitates the transformational leader's individualized consideration. Leaders in collectivist cultures already have a moral responsibility to take care of their subordinates, to help them prepare a career development plan, to attend their birthday parties, funeral ceremonies, and to counsel followers about personal problems. In turn, subordinates have a moral obligation to reciprocate with unquestioning loyalty and obedience. Indeed, transformational leadership may be far more pervasive in collectivist societies compared to the individualistic societies of the West (Jung, Sosik, \& Bass, 1995).

In turn, this may help to explain the fast economic development of the East Asian "Five Dragons" along with the favouritism and corruption due to social obligations that block the healthy competitiveness of free markets. Within the East-West context, other contingent relationships need further examination. These include the organization's culture and the transformational leaders' contribution to it, gender differences, and the importance of transformational leadership when leaders face the diversity of ethnicity, race, and sex among their followers. We need to learn in what ways individualistic cultures can gain the benefits of the collectivist cultures for transformational leadership without the associated costs in creativity, individual freedom, and initiative.

\section{Organizational Culture}

For an organizational culture to become more transformational, top management must articulate the changes that are required. The message may be of a vision which needs to be shared about the style of leadership the organization wants to emphasize. Thus, if it wants to tap the expertise of its members to the fullest, it may highlight its "consultative" style of leadership. Changes, consistent with this message, are introduced in the daily practices of the organization. Desired role models of leadership begin at the top and are encouraged at each successive level below. The behaviours of top level leaders become symbols of the organization's new culture. Stories are created around the leader and mechanisms are developed to improve upward communication.

Leaders who are concerned about organizational renewal will seek to foster organizational cultures that are hospitable and conducive to creativity, problem 
solving, risk taking, and experimentation. First, after deliberation and consultation, they articulate changes that are desired. Next, the necessary changes in structure, processes, and practices are made and are widely communicated throughout the organization. Stites-Doe, Pillai, and Meindl (1994) examined the occurrence of transformational leadership and the way the organizational culture is adopted by employees. They showed that individually considerate leaders will participate in more acculturation activities than those who are not. Many other aspects of how the organizational culture can affect and be affected by its leadership need to be examined as well (Bass \& Avolio, 1993b).

\section{Sex Differences}

Several studies have shown that women tend to be somewhat more transformational than their male counterparts and to some degree this is accompanied by greater satisfaction and rated effectiveness according to both male and female subordinates. Paradoxically, one might propose anti-feminine bias and disadvantage as a plausible explanation for finding that women are somewhat more transformational and therefore more likely to make effective leaders (Bass, Avolio, \& Atwater, 1996). Women may have to be that much better leaders than their male counterparts to attain the same positions of responsibility and levels of success as men. On the other hand, some may argue that affirmative action has pushed women faster and higher than justified by their competencies. Nevertheless, the military, industry, and government may be moving in the right direction in promoting relatively large numbers of women into positions of leadership. The doors have opened wide in first-level and middle management, but a glass ceiling remains in the elevation of women to top management positions, except in a few industries such as publishing and retailing.

New, better controlled, studies are needed. The majority of the organizations studied have been dominated by males. We need studies which match or adjust for abilities predictive of success as a leader. If we can equalize such capabilities, will women still emerge as more transformational than men as leaders? We need to examine what happens when women are in a majority, such as in nursing. Gottlieb (1990) completed such a study on nursing administrators in veteran's hospitals and emerged with challenging contrary findings.

\section{Diversity}

In an unpublished paper, Del Castillo (undated) defined cultural competency as a set of skills for maintaining a process of ethical balance between individual rights and responsibilities. Cultural competency involves: (1) understanding the methods by which individuals/groups perceive the world and develop conceptual schemes; (2) understanding one's own conceptual scheme; (3) integrating other views into one's respective conceptual schemes; and (4) valuing the diversity of 
all conceptual schemes. He then goes on to show that it would be transformational leaders who would be better prepared to value and adapt to diversity among their followers. The transformational leader was expected to envisage a culturally competent organization, to inspire confidence in its achievement, to use intellectual stimulation to encourage new ways of dealing with the increasing diversity of their followers and to be empathetic with their followers' different needs as individually considerate leaders.

\section{MEASUREMENT OF TRANSFORMATIONAL LEADERSHIP AND TRANSACTIONAL LEADERSHIP}

Much empirical knowledge about transformational and transactional leadership to date has been from survey research using the Multifactor Leadership Questionnaire for which problems remain of multicollinearity of its scales, lower than desired reliability under some circumstances for active managing-byexception, and questions about the universality of the factor structure of the model of the full range of leadership. Kelvin's admonition (originated by Camille Cavour) that "if you can't measure it, you don't know what you are talking about" drives the search for confirmation of understanding, theory and principles. Nevertheless, it was probably the Vietnam "body count" approach to evaluating the success of battles that gave rise to McNamara's Fallacy (Handy, 1994, p. 221):

The first step is to measure whatever can be easily measured. This is OK as far as it goes. The second step is to disregard that which can't be easily measured or to give it an arbitrary quantitative value. This is artificial and misleading. The third step is to presume that what can't be measured easily really isn't important. This is blindness. The fourth step is to say that what can't be easily measured really doesn't exist. This is suicide.

Leadership is as much emotional and subjective as rational and objective in effect. We need to appreciate what the non-quantitative scholars in psychohistory, sociology and political science have to say about charisma and transformational leadership such as Caro's (1982) biography of Lyndon Johnson and Kets de Vries' (1994) psychoanalytic views of defects in charismatic leadership.

\section{Issues in Measuring Transformational Leadership}

By relaxing Weber's (1924/1947) criteria for what is to be considered charismatic (Bass, 1985), and then including it as one of the four dimensions of transformational leadership as idealized influence, much has been learned about transformational leadership as well as charisma. We have developed a better understanding of the behaviours exhibited by such leaders, key personality 
characteristics underlying those behaviours, their impact, and how charismatic personalities develop. We have also learned that some of the traits attributed to charismatic are the same for one's immediate supervisor as for the distant worldclass leader. Other traits are different for immediate and distant charismatic leaders (Shamir, 1995).

Idealized influence. Idealized influence encompasses influence over ideology, influence over ideals, and influence over "bigger-than-life" issues. It was conceived as a substitute for the term charismatic for several reasons. First, charismatic had come to represent many meanings in the media and the public mind: celebrated, flamboyant, exciting, rabble-rousing, magnetic, and aweinspiring. Second, charisma was too much associated with dictatorship and pseudotransformational leaders such as Huey Long, Benito Mussolini, and Adolf Hitler. Third, for researchers such as House (1995) and Conger and Kanungo (1988), charisma was an all-inclusive term for transformational leadership taking in inspiration, intellectual stimulation, and individualized consideration. And so, for training and some research purposes, the term idealized influence was substituted for the charismatic factor (Bass \& Avolio, 1990a).

Charisma and Inspiration. In constructing the MLQ, the criterion of the principle of parsimony was violated when, for the purposes of fuller profile description, some of the items that are highly loaded and highly correlated (above 0.80 ) with the charismatic factor were formed to create a scale of inspirational motivation (see Bass, 1985, p. 214). This was done because it was believed that a leader could provide challenge and meaning through the use of simple words, slogans, symbols, and metaphors to generate acceptance of missions, without necessarily being charismatic. One did not have to identify with charismatic leaders to be aroused by them about the importance of a mission.

Repeated factor analyses have never supported the extraction of an inspirational factor from a charismatic factor. Yet there are separate bodies of literature for charismatic leadership and for inspirational leadership. The same leaders who are charismatic are also inspirational but different behaviours, attributions, and effects are involved. Tall people are heavier than short people but we still need separate scales of height and weight. Chapter 12 in Bass and Stogdill's Handbook of Leadership (Bass, 1990) divides itself into charismatic, charisma-like, and inspirational leadership. Not only are the behaviours, attributions, and effects different, but the relevant research literature is different. It may be that for purposes of quantitative study we should revert to a single factor encompassing charisma and inspirational leadership as Howell and Avolio (1993) did. However, McNamara's Fallacy (mentioned earlier) suggests that something may exist, such as the distinction between charisma and inspiration, without it being easy to measure. A confirmatory factor analysis for 3786 MLQ respondents suggests a good fit of the model for transformational leadership is 
given by three factors: individualized consideration, intellectual stimulation and inspirational-idealized influence (charisma) (Avolio, Bass, \& Jung, in press).

An equally large-scale confirmatory factor analysis by Podsakoff et al. (1990) suggested that six factors of transformational leadership could be distinguished. In addition to individualized consideration and intellectual stimulation, they were able to divide the charismatic-inspirational sector into identifying and articulating a vision, providing a model and setting the example, fostering acceptance of group goals, and setting high performance expectations.

Multicollinearity. Some factor studies such as an unpublished study of Air Force officers at Maxwell Field and a more recent study of Australian civil servants emerged with only a single factor of charisma or transformational leadership. This happens in some homogeneous samples, if short scales are used, with truncated versions of the MLQ. Nevertheless, three conceptually distinguishable factors-charisma-inspiration, intellectual stimulation, and individualized consideration-emerge in most studies either when using principal components factor analysis or when employing partial least squares (PLS) analysis (Avolio et al., in press). Since the transformational factors are substantially intercorrelated, a single transformational factor which combines them may satisfy the needs for parsimony in some research. Nevertheless, the three distinct factors instead of one transformational leadership factor remain useful when applied in training. Trainees can learn a lot about how to be more inspirational; they have a harder time authentically reinventing themselves as they already are intellectually stimulating.

It has been argued that the MLQ was measuring attributes and effects, not behaviours. None the less, most of the items of the MLQ concern behaviours. Only a few are attributions or effects. But particularly when assessing idealized influence, it is essential that some follower attributions be obtained because idealized influence involves the extraordinariness seen "in the eyes of the beholder" (Bass \& Avolio, 1993a). And so two highly correlated scales are assessed: idealized influence attributes, which "make us proud to be associated with him or her", and idealized influence behaviours, which "specify the importance of being committed to our beliefs".

The multicollinearity in the factors of transformational leadership presents a statistical problem even as we cross cultures, but the factorial structure remains. Mean scores on the factors may vary and some behaviours may become inappropriate. For instance, in Japan, contingent reward is more implicit than explicit. Nevertheless, the overall factor structure continues to provide a meaningful framework (Bass, 1997). While idealized influence (charisma) is the largest component of variance in transformational leadership, the other components of intellectual stimulation and individualized consideration are important 
theoretically and practically. They involve different behaviours, attributions, and effects. The abusive, abrasive, charismatic leader does not exhibit the same amount of individualized consideration as does the warm, socially concerned charismatic. The knowledge, skills, and abilities which may help one become more intellectually stimulating may be unconnected to one's individualized consideration.

\section{Issues in Measuring Transactional Leadership}

Transformational leadership adds to the effectiveness of transactional leadership; transformational leadership does not substitute for transactional leadership. Empirical studies of this augmentation effect (e.g. Waldman, Bass, \& Yammarino, 1990) support the original theoretical assumption (Bass, 1985). The best leaders are both transformational and transactional. Franklin Delano Roosevelt was a transactional politician as well as one of America's most transformational presidents (House, Spangler, \& Woycke, 1991).

In the first and many subsequent factor analyses, two transactional factors emerged. These were the two facets of contingent reinforcement, contingent reward, which "informs me about what I should do to be rewarded", and contingent aversive reinforcement (relabelled management-by-exception), which "takes no action unless a problem becomes serious". In military work, Yammarino and Bass (1990) also split contingent reward into promises (e.g. "clarifies what I will get if I succeed") and rewards (e.g. "gives me what I want in exchange for showing my support for him/her").

Less effective than the proactive contingent reward is management-byexception, which ranges in different situations from being slightly effective to slightly ineffective according to meta-analyses (e.g. Lowe, Kroeck, \& Sivasubramaniam, 1996). Hater and Bass (1988), Hoover (1987), and Yammarino and Bass (1990) all found it factorially valid to further split management-by-exception into an active factor such as "arranges to know when things go wrong" and a passive factor such as "subscribes to the belief that if it 'ain't broken, don't fix it". These divisions were further justified by subsequent factor analyses (Avolio et al., in press). Generally, active managing-by-exception is likely to be more effective than passive managing-by-exception.

Laissez-faire leadership, the avoidance of leadership, such as "is absent when needed", and "takes no action even when problems become chronic" was strongly associated with subordinate dissatisfaction, conflict, and ineffectiveness. But, early on, it included some items which assessed the more positive empowerment, such as "lets me decide on matters about which I know best". Empowerment by the leader implied giving followers autonomy but giving it with reason and interest in what was delegated. Empowerment items were removed from the most recent standardized version of the MLQ. 


\section{Levels of Leadership}

Before 1975, I was hard pressed to find the linkages between studies of leadership in small groups, leadership in formal organizations, and leadership of political and social movements. Now MLQ data and similar types of information can be gathered using the same concepts and full-range model across three levels of leadership (Yammarino \& Bass, 1991): leadership of the small group (microleadership), leadership of the large organization (macro-leadership), and leadership of movements and societies (meta-leadership) (Nicholls, 1990). Thus, we see applications at the micro-level (Hater \& Bass, 1988), at the macro-level (Yokochi, 1989), and at the meta-level (Bass, Avolio, \& Goodheim, 1987) of the same model of transformational leadership. It also generalizes in concept across nationalities and language (Bass, 1997).

\section{NEEDED FUTURE RESEARCH}

Applied research in transformational leadership has been abundant. Basic research and theory have been in short supply. We have made an effort to track all published and unpublished studies and to maintain the collection of reports, theses, dissertations, and journal articles in the library at our Center for Leadership Studies. All users of the experimental MLQ 5X are asked to submit copies of their results to the Mind Garden, the publisher of the MLQ and manuals (email: mindgarden@msn.com).

On the one hand, of the 200 reports to date, a large majority reconfirm the "correlational hierarchy". The transformational factors are usually found more highly correlated with outcomes in effectiveness and satisfaction of colleagues than is contingent reward. Contingent reward is ordinarily more highly correlated with outcomes than is managing-by-exception, particularly passive managingby-exception. Finally, laissez-faire leadership is almost uniformly negatively correlated with outcomes. There has been some demonstration of the contributions of transformational leadership to other criteria such as innovativeness and quality improvement. None the less, there has been relatively little basic research testing of the many models of linkages proposed by Bass (1985) to explain how transformational leadership works.

The closest to the promotion of fundamental understanding with empirical verification has come from work by Podsakoff et al. (1990), who have shown that trust is an important intervening construct. Theorization by Shamir, House and Arthur (1993) has connected the charismatic behaviour of the leader (which includes inspirational motivation, intellectual stimulation, and individualized consideration) with the self-concept and self-esteem needs of the follower, and Howell and Frost (1988), who, in testing House's 1976 Theory of Leadership (House, 1977), found that whereas initiation but not consideration could maintain high worker productivity when work group norms supported such productivity, only charismatic leadership could maintain high productivity in the face of 
conflicting low productivity norms. Recent contributions by House and Shamir (1993), and Shamir et al. (1993) have begun to "get to the bottom of things". These authors propose that transactional leaders focus on pragmatic paths to goals, whereas transformational leaders produce in their followers a higher: (1) salience of the collective identity in their self-concept; (2) sense of consistency between their self-concept and their actions on behalf of the leader and the collective; (3) level of self-esteem and a greater sense of self-worth; (4) similarity between their self-concept and their perception of the leader; (5) sense of collective efficacy; and (6) sense of "meaningfulness" in their work and lives.

By engaging follower self-concepts and arousing nonconscious motives of followers, the transformational leaders selectively arouse follower nonconscious achievement, affiliation, power motives (and other motives). These are nonconscious stable motives that have strong and enduring behavioural consequences. Such motive arousal results in increased engagement of the self, self-monitoring, and self-evaluation. The motive arousal engages the self-worth component of motivation and increases motivation on the part of followers.

Ultimately this leads to increased commitment to the mission since motive arousal results in increased self-engagement. Since the experience of self-worth and self-efficacy are contingent on goal attainment, it would be highly dissonant for the individual to resist commitment to the vision and mission of the leader. But yet to be explored are the many other ways that followers are transformed by leaders from concern for their self-interests to concern for their group, organization, or society. Self-interests are sacrificed because of: leader-inspired devotion to values and ideals embodied in the group; leader-inspired moral commitment to the group; leader-inspired identification with the group; leaderinspired calculation of the greater benefits to be gained from the group's success; and leader-inspired sense of obligations to serve the group ahead of oneself and a sense of loyalty to the group to defend its well-being and survival.

New methods need to be created for measuring transformational and transactional leadership. A new laboratory method appears promising to unravel the cause-effect relationships. Sosik, Avolio, and Kahai (1996) studied students linked by computer to a central server who were subjected to standardized transformational and transactional (contingent reward) messages both orally and via computer from trained confederate leaders who were in charge of the computerized group decision-support system. Transactional leaders generated a greater quantity of brainstorming suggestions but transformational leaders generated greater quality in the reports that were prepared.

We still need to learn a lot more about how perceptions differ between transformational and transactional leaders, dealing with what they think they ought to be doing in differing circumstances. Although the concepts of transformational and transactional leadership are found universally, much more still needs to be learned about how they are affected by the context in which the 
leadership occurs. Finally, much more explanation is needed about the workings of transformational leadership and how followers are moved from compliance, to identification, and to internalization of values and beliefs.

\section{REFERENCES}

Avolio, B.J. (1994). The "natural": Some antecedents to transformational leadership. International Journal of Public Administration, 17, 1559-1581.

Avolio, B.J., \& Bass, B.M. (1991). The full range of leadership development: Basic and advanced manuals. Binghamton, NY: Bass, Avolio, \& Associates.

Avolio, B.J., \& Bass, B.M. (1994). Evaluate the impact of transformational leadership training at individual, group, organizational and community levels. Final report to the W.K. Kellogg Foundation, Binghamton University, Binghamton, New York.

Avolio, B.J., Bass, B.M., \& Jung, D.I. (in press). Reexamining the components of transformational and transactional leadership using the Multifactor Leadership Questionnaire. Journal of Occupational and Organizational Psychology.

Avolio, B.J., \& Gibbons, T.C. (1988). Developing transformational leaders: A lifespan approach. In J.A. Conger \& R.N. Kanungo (Eds.), Charismatic leadership: The elusive factor in organizational effectiveness (pp. 276-308). San Francisco, CA: Jossey-Bass.

Bass, B.M. (1985). Leadership and performance beyond expectations. New York: Free Press.

Bass, B.M. (1990). Bass and Stogdill's handbook of leadership: Theory, research, and applications (3rd ed.). New York: Free Press.

Bass, B.M. (1997). Does the transactional/transformational leadership paradigm transcend organizational and national boundaries? American Psychologist, 52, 130-139.

Bass, B.M. (1998). Transformational leadership: Industrial, military and educational impact. Mahwah, NJ: Lawrence Erlbaum Associates Inc.

Bass, B.M., \& Avolio, B.J. (1990a). Manual for the Multifactor Leadership Questionnaire. Palo Alto, CA: Consulting Psychologist Press.

Bass, B.M., \& Avolio, B.J. (1990b). Training and development of transformational leadership: Looking to 1992 and beyond. European Journal of Industrial Training, 14, $21-27$.

Bass, B.M., \& Avolio, B.J. (1993a). Transformational leadership: A response to critiques. In M.M. Chemers \& R. Ayman (Eds.), Leadership theory and research: Perspectives and directions (pp. 49-80). New York: Academic Press.

Bass, B.M., \& Avolio, B.J. (1993b). Transformational leadership and organizational culture. Public Administration Quarterly, 17, 112-122.

Bass, B.M., \& Avolio, B.J. (1998). You can drag a horse to water but you can't make it drink. Journal of Leadership Studies, 5, 1-17.

Bass, B.M., Avolio, B.J., \& Atwater, L. (1996). The transformational and transactional leadership of men and women. International Review of Applied Psychology, 45, 5-34.

Bass, B.M., Avolio, B.J., \& Goodheim, L. (1987). Biography and the assessment of transformational leadership at the world-class level. Journal of Management, 13, 7-19.

Burns, J.M. (1978). Leadership. New York, NY: Harper \& Row.

Caro, R.A. (1982). The years of Lyndon Johnson: The path to power. New York: Knopf.

Conger, J.A., \& Kanungo, R.A. (1988). Charismatic leadership: The elusive factor in organization effectiveness. San Francisco: Jossey-Bass.

Del Castillo, S. (undated). The culturally competent transformational leader: A model for crosscultural leadership. Unpublished manuscript.

Gibbons, T.C. (1986). Revisiting: The question of born vs. made: Toward a theory of development of transformational leaders. Doctoral dissertation, Fielding Institute, Santa Barbara, CA. 
Gottlieb, T.W. (1990). Transactional and transformational leadership styles of chief and associate chief nurses in Department of Veterans 'Affairs Medical Centers: A descriptive study. Doctoral dissertation, Columbia University, DC.

Graen, G., \& Scandura, R.A. (1986). Toward a psychology of dyadic organizing. In B.M. Staw \& L.L. Cummings (Eds.), Research in organizational behaviour. Greenwich, CT: JAI Press.

Graen, G., \& Uhl-Bien, M. (1991). The transformation of professionals into self-managing and partially self-designing contributors: Toward a theory of leadership making. Journal of Management Systems, 42, 25-39.

Handy, C. (1994). Age of paradox. Cambridge, MA: Harvard Business School.

Hater, J.J., \& Bass, B.M. (1988). Superiors' evaluations and subordinates' perceptions of transformational and transactional leadership. Journal of Applied Psychology, 73(1), $695-702$.

Hoover, N.R. (1987). Transformational and transactional leadership: A test of the model. Doctoral dissertation, University of Louisville, KY.

House, R.J. (1977). A 1976 theory of charismatic leadership. In J.G. Hunt \& L.L. Larson (Eds.), Leadership: The cutting edge. Carbondale, IL: Southern Illinois University Press.

House, R.J. (1995). Leadership in the twenty-first century: A speculative inquiry. In A. Howard (Ed.), The changing nature of work. San Francisco: Jossey-Bass.

House, R.J., \& Shamir, B. (1993). Toward the integration of transformational, charismatic and visionary theories. In M.M. Chemers \& R. Ayman (Eds.), Leadership theory and research: Perspectives and directions. New York: Academic Press.

House, R.J., Spangler, W., \& Woycke, J. (1991). Personality and charisma in the US Presidency: A psychological theory of leader effectiveness. Administrative Science Quarterly, 36, 364-396.

Howell, J.M., \& Avolio, B.J. (1993). Transformational leadership, transactional leadership, locus of control, and support for innovation: Key predictors of consolidated business-unit performance. Journal of Applied Psychology, 78, 891-902.

Howell, J.M., \& Frost, P.J. (1988). A laboratory study of charismatic leadership. Organizational Behaviour and Human Decision Processes, 43, 243-269.

Jung, D.I., Sosik, J.J., \& Bass, B.M. (1995). Bridging leadership and cultures: A theoretical consideration of transformational leadership and collectivistic cultures. Journal of Management Inquiry, 2, 3-18.

Kets de Vries, M.F.R. (1994). The leadership mystique. Academy of Management Executive, 8, 73-92.

Kuhnert, K.W., \& Lewis, P. (1987). Transactional and transformational leadership: A constructive/developmental analysis. Academy of Management Review, 12, 648-657.

Lowe, K., Kroeck, K.G., \& Sivasubramaniam, N. (1996). Effectiveness of transformational and transactional leadership styles: A meta-analytic view. Leadership Quarterly, 7, 385-425.

Maslow, A.H. (1954). Motivation and personality. New York: Harper.

Nicholls, J. (1990). Rescuing leadership from Humpty Dumpty. Journal of General Management, 16, 76-90.

Podsakoff, P.M., MacKenzie, S.B., Moorman, R.H., \& Fetter, R. (1990). Transformational leader behaviours and their effects on followers' trust in leader, satisfaction, and organizational citizenship behaviours. Leadership Quarterly, 1, 107-142.

Seltzer, J., \& Bass, B.M. (1990). Transformational leadership: Beyond initiation and consideration. Journal of Management, 16, 693-703.

Shamir, B. (1995). Social distance and charisma: Theoretical notes and exploratory study. Leadership Quarterly, 6, 19-47.

Shamir, B., House, R.J., \& Arthur, M.B. (1993). The motivational effects of charismatic leadership: A self-concept based theory. Organization Science, 4, 577-594. 
Sosik, J., Avolio, B.J., \& Kahai, S.S. (1996). The impact of leadership style, anonymity, and group style on group potency and effectiveness in a group decision support system environment. Unpublished Paper, Academy of Management, Cincinnati, $\mathrm{OH}$.

Stites-Doe, S., Pillai, R., \& Meindl, J.R. (1994). Leadership style as a predictor of leaders' acculturating activity. Unpublished Paper, Southern Academy of Management, New Orleans, LA.

Tejeda, M.J., \& Scandura, T.A. (1994). Leader-member exchange: Exchange or charisma? Unpublished Paper, Southern Management Association, New Orleans, LA.

Waldman, D.A., Bass, B.M., \& Yammarino, F.J. (1990). Adding to contingent-reward behaviour: The augmenting effect of charismatic leadership. Group and Organizational Studies, 15, 381-394.

Weber, M. (1947). The theory of social and economic organizations (T. Parsons, Trans.). New York: Free Press. (Original work published 1924)

Williams, E.S. (1994). Tying up loose ends: The role of transformational leadership in OCBs, commitment, trust and fairness perceptions. Unpublished Paper, Southern Management Association, New Orleans, LA.

Yammarino, F.J., \& Bass, B.M. (1990). Long-term forecasting of transformational leadership and its effects among Naval officers: Some preliminary findings. In K.E. Clark \& M.R. Clark (Eds.), Measures of leadership (pp. 151-169). West Orange, NY: Leadership Library of America.

Yammarino, F.J., \& Bass, B.M. (1991). Person and situation views of leadership: A multiple levels of analysis approach. Leadership Quarterly, 2, 121-139.

Yokochi, N. (1989). Leadership styles of Japanese business executives and managers: Transformational and transactional. Doctoral dissertation. United States International University, San Diego, CA.

Yukl, G. (1989). Managerial leadership: A review of theory and research. Journal of Management, 15, 251-289.

\title{
Transactional vs. Transformational Leadership: Suggestions for Future Research
}

\author{
Christian Vandenberghe, Psychology Department, \\ Catholic University of Louvain, \\ Louvain-la-Neuve, Belgium
}

\begin{abstract}
A Commentary on "Two Decades of Research and Development in Transformational Leadership" by B. Bass
\end{abstract}

Bernard Bass provides a useful and insightful synthesis of past research on transformational leadership. He also points to important areas where empirical work has made substantial progress, and describes the issues over which much work is still needed. My commentary addresses these issues by examining more precisely what lines of investigations might be of value for enriching our understanding of transformational leadership and for learning more about the mechanisms through which it operates. 


\section{CONSTRUCT VALIDATION AND SUBSTANTIVE RELATIONSHIPS}

The Multifactor Leadership Questionnaire (MLQ) is widely used for measuring transactional and transformational leadership. As Bass summarizes, observed intercorrelations among MLQ transformational scales are quite high (cf. Lowe, Kroeck, \& Sivasubramaniam, 1996). Even the three basic transformational dimensions, that is, individualized consideration, intellectual stimulation, and idealized influence (charisma), are strongly correlated with each other in most studies. Moreover, it has not been shown that they consistently differ in their relationships with a set of criterion measures. What needs to be done if one purports to validate more rigorously the construct represented by each transformational facet (although this might be done for transactional scales too) is to specify a set of distinct correlates or consequences that might be associated with each component. The identification of distinct nomological nets for each component of the model is a critical phase of construct validation (Schwab, 1980). Specifying and testing interconstruct linkages can serve to clarify the content domain covered by each transformational (or transactional) facet. Obviously, this process is just starting in the transactional/transformational leadership domain. However, if efforts were not directed to issues of construct validity, it would be difficult to refine current measurement of the model's components and to determine if current scales suffer from construct deficiency or contamination (Schwab, 1980). In other words, attention drawn towards issues of construct validity is necessary to determine if transformational leadership is multidimensional or unidimensional.

With respect to transformational leadership facets, past research provides some insights into specific linkages with key criteria. For example, intellectual stimulation might have a positive effect on burnout (cf. Seltzer, Numerof, \& Bass, 1989), especially in professions already exposed to much sources of stress in their work environment (e.g. nurses, teachers). Determining the conditions under which intellectual stimulation has negative vs. positive consequences for employees could enrich our understanding of its meaning and implications. Under conditions of low stress, stimulating intellectually one's employees can result in more creativity and innovative behaviour. In contrast, under high stress, intellectual stimulation may be a source of role overload.

Similarly, it has been argued that transformational leadership acts upon subordinates' self-esteem and self-concept (Shamir, House, \& Arthur, 1993). However, current definitions of transformational components suggest that it is through idealized influence (charisma) that leaders can best close the gap between the organization's mission and the individuals' self-concept. Investigators should determine which transformational component is most strongly associated with employees' sense of identity and self-esteem. Finally, individualized consideration might be related to individuals' needs for support and 
personal growth. Alternatively, individualized consideration could have detrimental effects in specific contexts. Recently, we collected some data using the MLQ in operating rooms (Vandenberghe \& Gobert, 1996). We found that individualized consideration resulted in less satisfaction with the leader. Post-hoc interviews with some nurses from these operating units revealed that a head nurse who was individually considerate was perceived as threatening the nursing team. In fact, nurses perceived individualized consideration by the head nurse as a mark of favouritism and inequity.

The proposed hypothetical linkages are but a few examples of relationships of a more integrated nomological net that could be derived from theory and past research to sustain the construct validation of the transactional/transformational leadership model.

\section{PERSONALITY ATTRIBUTES}

Bass states that transformational leadership qualities are affected by individuals' childhood experiences. Further, he reports research showing that transformational leaders typically report their parents as being caring and setting challenging goals. One can push this argument further and assume that transformational leaders have distinct personality attributes that are different from those characterizing their transactional counterparts. Although this kind of research is still in its infancy, some studies have shown that transformational leaders exhibit specific personality attributes (Atwater \& Yammarino, 1993; Dubinsky, Yammarino, \& Jolson, 1995; Ross \& Offermann, 1997). For example, Ross and Offermann (1997) demonstrated that high scores on transformational leadership were associated with a pattern of personality including high levels of pragmatism, nurturance, feminine attributes, and self-confidence, and low levels of criticalness and aggressiveness. A weakness of that study, however, is that it did not rule out the possibility that these attributes were also characteristic of transactional leadership since that component was unmeasured. So, future research should examine in a more systematic way how transformational leaders differ in their personality attributes from transactional ones and how these differences may explain subordinates' and/or unit performance.

An intriguing finding of Ross and Offermann's (1997) study is that personality attributes correlated with transformational leadership are qualities traditionally associated with females' role in our society: "a less aggressive and more nurturant leader" (Ross \& Offermann, 1997, p. 1084). This picture is consistent with recent findings suggesting that female managers are more transformational than their male counterparts (Bass, Avolio, \& Atwater, 1996). However, as Bass judiciously indicates, more research is needed to determine if true gender differences are responsible for current findings or whether these results can be attributed to differences in competencies between males and females (females having to strive harder and show more competencies to reach 
the same positions as men). Obviously, research examining the linkages between gender, personality, and transformational leadership is warranted.

\section{TRAINING AND DEVELOPMENT}

The preceding topic calls for another, important issue, that of training and development: Can one learn to be a transformational leader? To date, scant research attention has been devoted to this issue. Bass presents some general information concerning the (positive) results yielded by his "Full Range of Leadership Development" programme among a variety of managers and executives. However, more controlled and elaborated designs are needed to test the idea that transformational leadership can be learned and be associated with significant improvements in unit performance. In this regard, Barling, Weber, and Kelloway (1996) conducted a field experiment to assess the attitudinal and financial outcomes of a training session in transformational leadership within the banking industry. Using a pretest-posttest control group design, they showed that managers who received training were rated by their subordinates as being more transformational. The training programme followed by managers also significantly affected the subsequent organizational commitment of subordinates. Finally, evidence was also reported that branches in which managers followed the training session displayed better financial outcomes.

More (quasi-)experimental studies are needed to test the hypothesis that transformational leadership can be learned and that changes in transformational behaviours displayed by managers are responsible for increased unit performance. Moreover, researchers should establish if training in transformational leadership has comparatively more positive effects than training in the more traditional transactional leadership. Finally, longitudinal designs would be necessary for assessing the stability of effects and for determining the appropriate time lag required for leadership training sessions to exert their effects.

\section{CONTEXTUAL INFLUENCES}

A complex issue in studying leadership concerns its contextual influences. Bass does a good job of identifying contingencies that can affect transformational leaders' actions. As an example, he suggests that some organizational cultures are better hosts for transformational leaders than others. Bass (1996) describes data showing that organizational cultures described as transformational are viewed as doing more for improving the quality of products or services. In a similar vein, one may suggest that some organizational values are more conducive to transformational leadership. Recently, Den Hartog, Van Muijen, and Koopman (1996) demonstrated that departments with a leader described as transformational were viewed as emphasizing primarily values of support and innovation. 
More basically, it might be that some contexts are propitious to the emergence of transformational leadership whereas others are not. Pawar and Eastman (1997) theorized that organizations differ in their receptivity to transformational leadership. In essence, they proposed that organizational receptivity varies from a negative to a positive pole. The positive pole refers to organizations (1) undergoing a period of change necessitating adaptation, (2) dominated by boundaryspanning units for dealing with environmental uncertainty, (3) characterized by a simple or an adhocratic organizational structure (i.e. structures facilitating the development of vision), or (4) with a clan mode of governance that creates an alignment between members' self-interests and the collective mission. These characteristics would facilitate the emergence of transformational leadership. The negative pole of organizational receptivity refers to organizations (1) focusing on efficiency, (2) with a task system dominated by technical cores (i.e. oriented towards predictability rather than management of uncertainty), (3) pertaining to the machine bureaucracy, professional, or divisional type of structure, or (4) with a market or bureaucratic rather than a clan mode of governance. These characteristics would generate a weak level of organizational receptivity to transformational leadership.

Although Pawar and Eastman's theory calls for empirical validation, its merit lies in proposing testable hypotheses regarding linkages between Bass's model and contextual variables. Our own work (Stordeur, Vandenberghe, \& D'hoore, in press) suggests that professional organizations such as hospitals may indeed belong to the negative zone of organizational receptivity to transformational leadership. Hospitals are traditionally characterized by a lack of vision creation and implementation because professionals (nurses, physicians, etc.) are weakly committed to the organization. Using a sample of eight hospitals, we found that the scores on transformational scales obtained by nursing executives were unrelated to those developed at lower levels in the nursing ladder. This contradicts the so-called "falling dominoes effect", which states that transformational leadership displayed at the top level tends to be replicated at the next lower level of the hierarchy (Bass, Waldman, Avolio, \& Bebb, 1987). The reason for our finding may be that hospitals are weakly receptive to transformational leadership. Additional research is needed to test the other contextual influences identified by Pawar and Eastman.

\section{SEARCHING FOR MEDIATORS}

In his final comments, Bass outlines several areas where research efforts are needed. In particular, he proposes that more work should address the mediating linkages between transformational leadership and work outcomes. Further, he identifies trust and individuals' self-concept as two constructs that are potential mediators of transformational leadership effects. However, Bass overlooks a 
construct that may still be a powerful mediating variable-psychological empowerment.

Thomas and Velthouse (1990) and Spreitzer (1995) define psychological empowerment as a psychological state subsuming four interrelated cognitions: meaning, competence, self-determination, and impact. Meaning refers to the perceived fit between the individual's values and beliefs, and the requirements of a work role. Competence is self-efficacy related to one's job. Self-determination is the felt autonomy in initiating actions at work. Finally, impact refers to the ability of an individual to influence the strategic, administrative, or operating outcomes at work. One may hypothesize that some transformational leadership facets act through empowerment in influencing work outcomes. For example, charisma may provide a sense of meaning which in turn could enhance organizational commitment. Intellectual stimulation should influence subordinates' felt competence and lead to higher in-role performance. Individualized consideration may foster self-determination and impact and indirectly result in more intrinsic job satisfaction. Additional hypotheses concerning potential mediating linkages between transformational leader behaviours and organizationally relevant outcomes could be formulated and empirically tested.

\section{CONCLUSION}

Bernard Bass's article offers a good synthesis of what we have learned and what remains to be learned about the transformational leadership workings. However, progress will be achieved only if theory building efforts lead to precise hypotheses to be tested. In this commentary, I focused on five areas of needed research: (1) construct validation (the linkage between a construct and its measurement), (2) personality attributes of transactional and transformational leaders, (3) effects of training in transformational skills on organizational outcomes, (4) contextual influences, and (5) the search for mediators.

\section{REFERENCES}

Atwater, L.E., \& Yammarino, F.J. (1993). Personal attributes as predictors of superiors' and subordinates' perceptions of military academy leadership. Human Relations, 46, 645-668.

Barling, J., Weber, T., \& Kelloway, E.K. (1996). Effects of transformational leadership training on attitudinal and financial outcomes: A field experiment. Journal of Applied Psychology, 81, $827-832$.

Bass, B.M. (1996). A new paradigm of leadership: An inquiry into transformational leadership. Alexandria, VA: US Army Research Institute for the Behavioral and Social Sciences.

Bass, B.M., Avolio, B.J., \& Atwater, L. (1996). The transformational and transactional leadership of men and women. Applied Psychology: An International Review, 45, 5-34.

Bass, B.M., Waldman, D.A., Avolio, B.J., \& Bebb, M. (1987). Transformational leadership and the falling dominoes effect. Group and Organization Studies, 12, $73-87$.

Den Hartog, D.N., Van Muijen, J.J., \& Koopman, P.L. (1996). Linking transformational leadership and organizational culture. Journal of Leadership Studies, 3, 68-83. 
Dubinsky, A.J., Yammarino, F.J., \& Jolson, M.A. (1995). An examination of linkages between personal characteristics and dimensions of transformational leadership. Journal of Business and Psychology, 9, 315-335.

Lowe, K.B., Kroeck, K.G., \& Sivasubramaniam, N. (1996). Effectiveness correlates of transformational and transactional leadership: A meta-analytic review of the MLQ literature. Leadership Quarterly, 7, 385-425.

Pawar, B.S., \& Eastman, K.K. (1997). The nature and implications of contextual influences on transformational leadership: A conceptual examination. Academy of Management Review, 22, $80-109$.

Ross, S.M., \& Offermann, L.R. (1997). Transformational leaders: Measurement of personality attributes and work group performance. Personality and Social Psychology Bulletin, 23, 1078-1086.

Schwab, D.P. (1980). Construct validity in organizational research. Research in Organizational Behavior, 2, 3-43.

Seltzer, J., Numerof, R.E., \& Bass, B.M. (1989). Transformational leadership: Is it a source of more burnout and stress? Journal of Health and Human Resources Administration, 12, $174-185$.

Shamir, B., House, R.J., \& Arthur, M.B. (1993). The motivational effects of charismatic leadership: A self-concept based theory. Organization Science, 4, 577-594.

Spreitzer, G.M. (1995). Psychological empowerment in the workplace: Dimensions, measurement, and validation. Academy of Management Journal, 38, 1442-1465.

Stordeur, S., Vandenberghe, C., \& D'hoore, W. (in press). Leadership styles across hierarchical levels in nursing departments. Nursing Research.

Thomas, K.W., \& Velthouse, B.A. (1990). Cognitive elements of empowerment. Academy of Management Review, 15, 666-681.

Vandenberghe, C., \& Gobert, P. (1996). Transformational leadership, transactional leadership, job scope, and culture in nursing subunits: How they relate to work outcomes. Unpublished manuscript. Catholic University of Louvain, Louvain-la-Neuve, Belgium. 
Copyright of European Journal of Work \& Organizational Psychology is the property of Psychology Press (T\&F) and its content may not be copied or emailed to multiple sites or posted to a listserv without the copyright holder's express written permission. However, users may print, download, or email articles for individual use. 